\title{
Services integration for injection drug users on antiretroviral therapy for management of HIV epidemic in Estonia
}

\author{
Kaja-Triin Laisaar ${ }^{1 *}$, Anneli Uusküla ${ }^{1}$, Anjali Sharma² $^{2}$ Jack DeHovitz ${ }^{2}$ \\ From $16^{\text {th }}$ International Symposium on HIV and Emerging Infectious Diseases \\ Marseille, France. 24-26 March 2010
}

\section{Background}

To assess coverage of harm reduction services for HIVinfected patients in Estonia and their integration with HIV care; to identify barriers to integrated services provision.

\section{Methods}

We reviewed HIV surveillance documents, administrative data and scientific literature, and interviewed key informants providing treatment and harm reduction services in North-Eastern county of Estonia.

\section{Results}

Estonia had the highest incidence of HIV infection in Europe with 472 cases per million and an adult HIV prevalence of $1,3 \%$ in 2007, the second-highest in Europe. Majority of new cases occur in the North-Eastern county, with incidence exceeding 4 times that of Estonia as a whole (183 vs 47 per 100 000). The Estonian epidemic is driven by injection drug use, and local studies have revealed a $40-90 \%$ prevalence of HIV among injection drug users (IDUs). HIV treatment is provided by state-funded public health-care system. At end of 2008 1006 patients were receiving HAART. Harm reduction services are provided by non-profit organizations (usually state funded). There are 7 centers for methadone substitution therapy (649 patients treated at end of 2008); 36 syringe exchange programs; 2 centers for free and anonymous STI services. Yet in different regions only $6-28 \%$ of IDUs report currently receiving treatment for drug use and $5-12 \%$ receiving HAART. The main challenge and strategic goal of the National HIV/AIDS Prevention Strategy remains coverage of IDUs by treatment and harm reduction services. The major barrier identified was failure to provide well integrated services to those in need. The underlying factors leading to the barrier were substantial misperceptions in regards to the utility of methadone substitution therapy among HIV medical care providers.

\section{Discussion}

In the current resource constrained environment improvement and integration of already existing services would ensure sustainability of the national HIV prevention strategy. Barriers to integration need to be delineated and addressed.

\section{Author details}

'Department of Public Health, University of Tartu, Tartu, Estonia. ${ }^{2}$ Downstate Medical Center, State University of New York, Brooklyn, USA.

Published: 11 May 2010

doi:10.1186/1742-4690-7-S1-P142

Cite this article as: Laisaar et al:: Services integration for injection drug users on antiretroviral therapy for management of HIV epidemic in Estonia. Retrovirology 2010 7(Suppl 1):P142.

\footnotetext{
* Correspondence: kaja-triin.laisaar@ut.ee

${ }^{1}$ Department of Public Health, University of Tartu, Tartu, Estonia
} 